\title{
Strong and Weak Dialects of China: How Cantonese Succeeded Whereas Shaan'Xi Failed with the Help of Media
}

\author{
Mao Yu-Han ${ }^{1} \&$ Hugo Yu-Hsiu Lee ${ }^{1}$ \\ 1 Graduate School of Language and Communication, National Institute of Development Administration, \\ Thailand \\ Correspondence: Hugo Yu-Hsiu Lee, Graduate School of Language and Communication, National Institute of \\ Development Administration, Bangkok, Thailand. Tel: 88-607-2560. E-mail: YL15@umail.iu.edu
}

Received: April 5, $2014 \quad$ Accepted: June 4, $2014 \quad$ Online Published: July 11, 2014
$\begin{aligned} & \text { doi:10.5539/ass.v10n15p23 } \\ & \text { URL: http://dx.doi.org/10.5539/ass.v10n15p23 }\end{aligned}$

\begin{abstract}
This research addresses an important set of social scientific issues-how language maintenance between dominant and vernacular varieties of speech — also known as dialects - are conditioned by increasingly globalized mass media industries that are created by them and accompany them. In particular, it examines how the television series and film industries (as an outgrowth of the mass media) related to social dialectology help maintain and promote one regional variety of speech over the other. The value of this thesis is ultimately judged by its contribution to the sociolinguistic literature. All of these issues and data addressed in the current study have the potential to make a contribution to the current understanding of social dialectology literature-a sub-branch of sociolinguistics - particularly with respect to the language maintenance literature. The researcher adopts a multi-method approach (literature review, interviews and observations) to collect and analyze data. The research is found support to confirm two positive correlations: the number of production of dialectal television series (and films) and the distribution of the dialect in question, as well as the number of dialectal speakers and the maintenance of the dialect under investigation.
\end{abstract}

Keywords: Chinese dialects, Cantonese, Shaan'Xi, language maintenance, media

\section{Introduction}

\subsection{Overview}

A fundamental question of social science (particularly with regard to sociolinguistics/sociology of language) is what makes some languages and/or dialects more powerful than others and what are reasons behind such a difference? Over the past 30 or more years, this question has been predominantly approached by means of sociolinguistic measures such as a domain-based questionnaire - a language-use survey - to obtain self-reported language-use (quantitative) data across various functional and communicative domains (e.g., Gal, 1978; Smith-Hefner, 2009; Mukherjee and David, 2011; to name but a few), aimed to measure the respondents' vitality perceptions of the language in question. Additionally, others conduct the quantitative survey to elicit language-attitude data among majority or minority speech community members toward a particular language (e.g., Sallabank, 2013).

Following the recent trend of the aforementioned sociolinguistic research, this study examines the role of mass media (major factor) and the number of dialectal speakers (minor factor) in conditioning linguistic variation by means of qualitative approaches (e.g., literature review, interview and observation) rather than quantitative measures (e.g., a questionnaire survey).

\subsubsection{Defining the Terminology}

In the multidisciplinary discipline of language maintenance (henceforth LM), there is increasingly a growing concern on the vitality of smaller speech communities and language-user groups. The present study joins this trend and examines the sustainability status of more dominant Chinese varieties of speech-also known as the Chinese dialects (方言 fāngyán) — vis-à-vis less powerful ones spoken in the Mainland China. However, from the point of view of linguistic typology, the distinction between a dialect and a language is problematic, because the difference among dialects is great enough to be considered them as separated languages. Therefore, in addition to the terms of 'varieties' of regional speech customarily translated into English as 'dialects,' it is 
essential to acknowledge that the term of 'ethnic language' is also adopted to refer to the respective languages of the Chinese dialect groups under study. For a detailed discussion of defining operational terminology of local forms of speech in the Mainland China, please see Kurpaska (2010, 1-3, emphasis in original.)

\subsubsection{Purpose of the Study}

An analysis of the language variation in the polyglot nation-state of China will better help our current understanding of the reasons behind the success and the failure of LM. The researcher aims to illustrate the role of mass media (major factor) played on the maintenance of more powerful Chinese dialects (e.g., Cantonese) and the role of the number of dialectal speakers (minor factor) played on the maintenance of the well-sustained Chinese dialects (e.g., Cantonese) and on the shifting of the less-maintained Chinese dialects (e.g., Shaan'Xi).

The specific objectives of the study are as follows: (1) compare and examine the extent of the dialect of Cantonese vis-à-vis the dialect of Shaan'Xi in the selected functional domains of mass media in respect to the language distribution, spread and maintenance; and (2) identify and recognize social variables which influence the maintenance of the aforementioned dialects researched.

\subsection{Chinese Dialects}

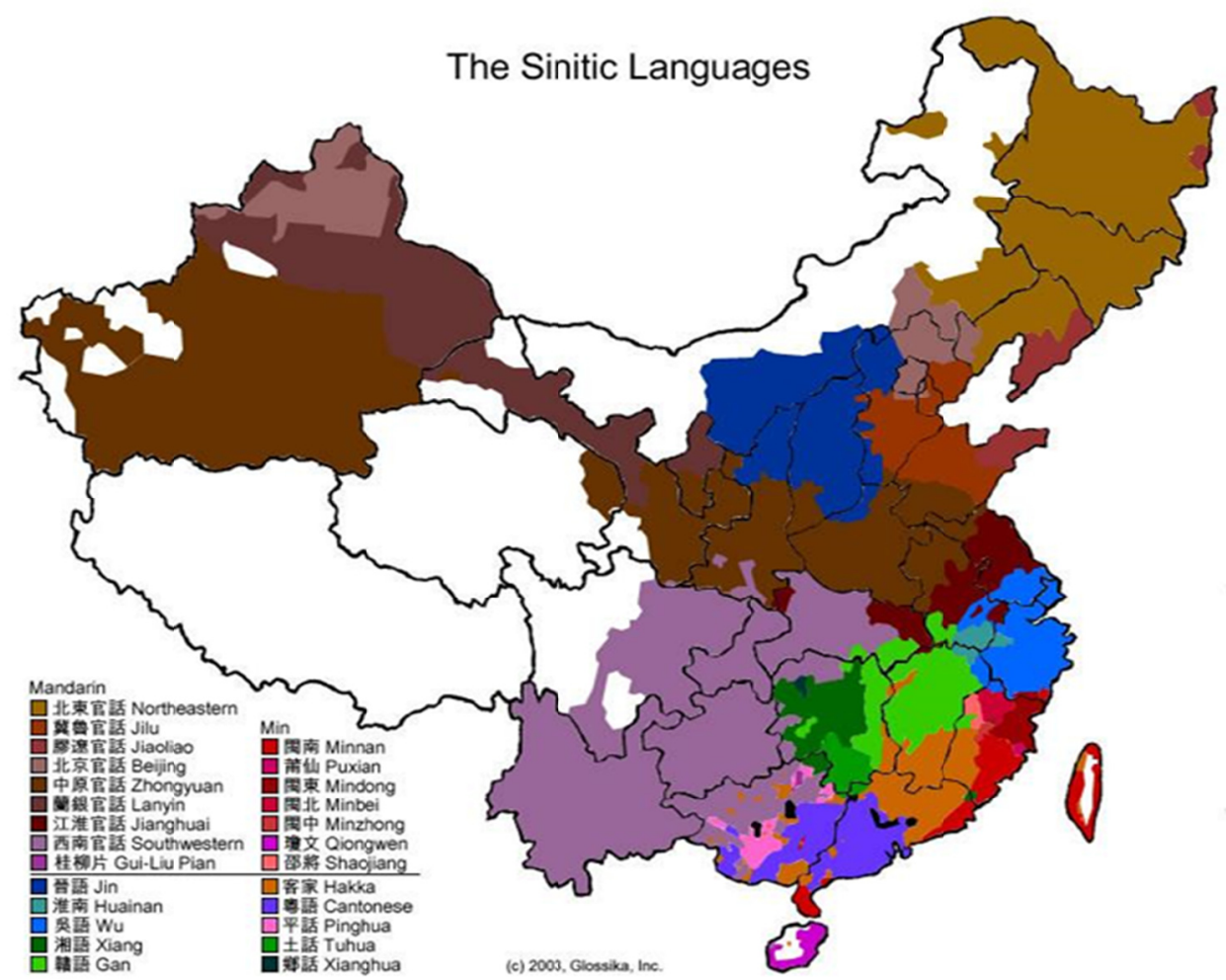

Figure 1. The distribution of Chinese dialects (c) 2003, Glossika, Inc

Retrieved on December 24th 2013 from the Web Site: http://image.baidu.com

This present sub-section provides an introductory and selective review of theoretical and empirical classification of Chinese dialects by defining terminology and providing the background of the study. For a fuller discussion of the classification of Chinese dialects, see Kurpaska (2010, 25-62, emphasis in original).

It is widely recognized that the Mainland China is a modern nation-state with a vast territory and it can be divided into numerous geographical regions (Chun, 2006), a large melting pot of numerous discrepant ethnicities and ethno-cultures. It is essential to know that ethno-cultures, ethnicities, geographies and so forth affect the extent of the formation of ethno-dialectical communities in the Mainland China (Sha, 2012).

Both historically and currently, the anthropological and sociolinguistic situations in the Mainland China have been highly debated by Chinese and non-Chinese scholars, given its plentiful varieties of local speech. It is estimated that ethno-cultural diversities are manifest across the Mainland China in innumerable realms - ethnic languages, cuisines, costumes, and religions and so forth. Particularly regional dialects in the Mainland China 
not only reflect its own unique cultures, environments, geographies, histories and so on, but it also reflects its political policies. Linguistic diversity is an indicator of other forms of ethno-cultural diversity which exist among the dialect groups in question. Dialects are seen as the most direct interpretation of local ethno-cultures, yet dialects underwent variations and changes because they progressed and transited at different timescales (Wang, 2011). By the same token, it is argued that the varieties of speech play a major role in this process of formation and segregation of ethno-dialectical communities. It implies that the comprehension of dialects entails a grasp of historical events and episodes, because dialects are seen as communicative tools, folkloric habits and ways of thinking beyond the cultural per se (Lin, 2008).

Over the past 80 or so years, a great deal of empirical research has focused on the classification of Chinese dialects. Initially proposed by the Wang Li (1936) (some argued for Li Fang-Kuei, 1937), his classification of the Chinese dialects is the first of its kind. Numerous attempts have been put forth by both Chinese and non-Chinese scholars to the reformulation of the re-classification of Chinese dialects (see Zhan, 1981; Norman, 1988; Ding, 1998 and Li, 2002; to name but a few). In spite of their debate, they tended to agree with seven major Chinese dialect groups (Kurpaska, 2010). Therefore, instead of reiterating what has been surveyed and described by the aforementioned linguists, below is a big picture of comparatively powerful Chinese dialect groups by identifying and highlighting their importance and significance, respectively.

It should be acknowledged that a comprehensive treatment of the facts and the issues relating to the respective ethnic languages spoken in the Mainland China is nearly impossible, due largely to the space available in the current thesis. It is hoped by the author, nonetheless, this sub-section offers a selective overview of the Chinese dialects in consideration.

\subsubsection{Powerful Chinese Dialects}

The list below consists of 7 major Chinese dialect groups (Wang, 1936; Li, 1937; Zhan, 1981; Norman, 1988; Ding, 1998 and Li, 2002). At present, Mandarin (普通話 pǔtōnghuà; the Northern Chinese dialect) (literally 'common speech') is spoken in the Northern and the Southwestern China, which makes up the largest spoken variety in the Mainland China. It is the official state language and the inter-ethnic lingua franca in both People's Republic of China (PRC) and Republic of China in Taiwan (ROC). Moreover, it is one of the official state languages in the island state of Singapore.

Additionally, $\mathrm{Wu}$ (吳語 wúyǔ; the dialect spoken in the South of the Changjiang River) is spoken in the Jiangsu Province and the Zhejiang Province, as well as the municipality of Shanghai. Despite the fact that the diversification of subgroups of the $\mathrm{Wu}$ variety of speech (particularly with regard to the mountainous regions of Zhejiang and Eastern Anhui) results in a mutual unintelligibility among speakers of disparate subgroups, the Shanghai dialect is commonly regarded as a representative of the dialect group in question.

Furthermore, Yue (奥語 yuèyǔ) is spoken in Guangdong, Guangxi, Hong Kong, Macau, parts of Southeast Asia (mainland and insular) and overseas Chinese communities of the Guangdong ancestry. The term "Cantonese" is commonly referred to encompass all the Yue varieties, notwithstanding the fact that they are not mutually intelligible.

Undoubtedly, Min (閩語 mǐnyǔ) is spoken in the Fujian Province of the Mainland China, the island state of Taiwan, parts of Southeast Asia (mainland and insular) particularly in Malaysia, Philippines, and Singapore, and overseas Chinese communities (e.g., China Town in the New York City of the United States of America) of Fujian ancestry. It is widely recognized that the Southern Min (Min Nan) dialect is the largest Min variety of speech spoken across its speakers' homeland and resettled nation-states.

In the literature, Xiang (湘語 xiāngyǔ) is spoken in the Hunan Province of the Mainland China and it is commonly divided into the old and the new dialects respectively (the new Xiang dialect is under tremendous influence of the Mandarin, because of the contact between new Xiang speakers and the Mandarin speakers and media across various functional language domains).

From the actual empirical data, Ke Jia (Hakka) (客家話 kèjiāhuà) is spoken by the Hakka people across numerous provinces in Southern China and the island state of Taiwan, and parts of Southeast Asia (mainland and insular) in Malaysia and Singapore. The term 'Hakka' literally means "guest families," inasmuch as numerous Hakka people regard themselves as refugees derived from the Northern China (This viewpoint is highly debated).

In combination with all the 6 aforementioned dialect groups, Gan (赣語 gànyŭ) is regarded as a powerful dialect family and is spoken in the Jaingxi Province of the Mainland China. It is viewed as a closer relative to the Hakka 
variety of speech, because of their similarities in phonology. Therefore, they are referred to as "Hakka-Gan dialects."

\subsubsection{The Most Powerful Chinese Dialect and the Cantonese Community in China}

The current sub-section provides a selective review of the Cantonese dialect and the Cantonese people. Across numerous studies that examine the maintenance and the shift of Chinese dialects, it has emerged that, of all the above-mentioned major Chinese dialect groups and their regional varieties of speech, Cantonese (or Yue) has frequently been called "the most powerful Chinese dialect" by scholars (Xu, 2012). With more than 70,000,000 speakers, the Cantonese community is one of the largest in the Mainland China (People's Government of Guangdong Provence, 2007). It is believed that no other Chinese dialects apparently parallel the extraordinary standing and achievements of the Cantonese dialect, inasmuch as its massive number of speakers and the important role the speech community members play in social and economic sectors, particularly in the mass media (in the Mainland China, neighboring areas outside the Mainland China and abroad).

In particular, the Cantonese dialect is viewed as an inter-ethnic lingua franca for the Cantonese people in communicating with other ethnic groups and vice versa in the Guangdong Province of the Mainland China. Additionally, it is spoken by the predominant majority of population in neighboring areas of Hong Kong (de facto official language) and Macau (outside the Mainland China), and overseas Chinese communities in Southeast Asia (e.g., Malaysia), Asia pacific (e.g., Australia and New Zeeland), North America (e.g., United States of American and Canada) and Europe (e.g., Germany). Nearly all of them originate from the Guangdong Province of the Mainland China or of the Guangdong ancestry. Among and across all the above-mentioned Cantonese speech communities, Hong Kong is regarded as the hub of the Cantonese culture, inasmuch as its influence of mass media and pop culture for nearly seventy or more years. For a review Hong Kong's linguistic variation, see $\mathrm{Lu}$ (2002).

In addition to the investigation of the Cantonese speech communities and language-user groups in the Mainland China which can be found in the extant literature, much of the classical sociolinguistic literature on the issue of language maintenance and shift among overseas Cantonese speech communities and language-user groupsis reported from Australia, Canada, New Zeeland, the United States of America, the United Kingdom, and Southeast Asia. They commonly include an assessment of the status (e.g., economic value) and institutional support (e.g., mass media) for promoting the Cantonese speech. For reviews of these aforementioned reports, see Giles et al. (1977) for the institutional support and language maintenance, see Appel \& Muysken (1987) for promoting the language by means of mass media, and see Wang \& Chong (2011) for the highly cited report on the successful maintenance of the overseas Cantonese speech community in the nation-state of Malaysia. As a complement to previous data, this current study particularly examines the sociological variable known as the institutional support in view of the mass media as the major factor governing the maintenance and the shift of the two varieties of speech in question.

\subsubsection{Less Powerful Chinese Dialects and the Shaan'Xi Community in China}

One of the numerous effects of the implementation of the national language policy and the language-in-education policy in the Mainland China is language endangerment. It has eventually become apparent that ethnic languages and regional varieties of speech are replaced by the official state language in the nation-state of Mainland China. In the reexamination of endangered Chinese dialects based upon Cao's (2001), Yang's and Xu's (2009) and Tang's (2010) data, the Han-Chinese dialect spoken by the nine-family-name fish men (九姓漁民 jiǔ xìng yú mín), the local Chinese vernacular of She (墖話 shē huà) and the Heilongjiang Zhan dialect (黑龍江站話 hēi long jiāng zhàn huà) are extremely endangered, among others.

Among the estimated three-thousand dying dialects (UNESCO, 2006, as cited in Lin, 2011), Shaan'Xi is perceived to be one of the endangered Chinese dialect in spite of its great past. It is a truism that the Shaan'Xi Province of the Mainland China is regarded as one of the cradles of ancient and imperial Chinese civilizations, due largely to the fact that it was the great ancient capital for thirteen dynasties over the period of 1,100 years (from the Zhou Dynasty to the Tang Dynasty). Despite this, substantial evidence can be marshaled to point out the fact that the Shaan'Xi variety of speech — not only the ethnic language of the Shaan'Xi speech community, but also the language used to establish the great ancient Chinese civilization, is endangered in the twenty-first century. For an overview of the characteristics of the Shaan'Xi speech community, see Peng (2013).

It is evident that studies measuring the vitality of ethnic languages encounter difficulties in demonstrating what are the discrepancies between relatively more powerful codes of communication (e.g., Cantonese) and less dominant ones (e.g., Shaan'Xi). This study aims to contrast the two aforementioned regional varieties of speech 
by examining factors such as mass media (e.g., films) and speaking population that to a greater or lesser extent they play in the maintenance of the two dialects in question.

Taken together, the objectives of the preceding sub-section are to sketch out the current conditions of the Cantonese dialect as a representative of one of the most powerful Chinese dialect groups in contrasted to less powerful ones such as the Shaan'Xi dialect, the proceeding section of results and discussion section will trace their differential conditions and explore some of the factors for their discrepancies.

\section{Literature Review}

\subsection{Overview}

This section of the study is a selective overview of the recent theoretical and empirical advances in the all-encompassing field of sociolinguistics or sociology of language, particularly with regard to the study of social dialectology - $\mathrm{a}$ branch of sociolinguistics - and the maintenance (and the shift) of the regional varieties of speech-formerly known as the dialects. It should be noted that many of the conventional concepts in LM are extended and redefined to reflect the theoretical and empirical emphasis in the current study.

\subsection{Re-Examining the Theoretical and Empirical Perspectives of Language Maintenance (LM)}

The present study is informed by numerous theories and perspectives. One approach which guides the research is language maintenance (LM). Traditionally, LM is viewed from three different perspectives (Baker and Jones, 1998, 181-185). The inactive preservationist viewpoint is seemly to maintain the status quo of the variety of speech in consideration instead of implementing a measure of language development. By contrast, the evolutionist point of view argues the 'survival of the fittest' (more powerful languages will survive, whereas less powerful ones will die out). Lastly, the active conservationist view is regarded as the most proactive one among the three, inasmuch as it takes conscious and deliberate language planning efforts to ensure the maintenance of minority languages. It should be noted that the researcher of the current study is in agreement with the conservationist view.

Relating to the above-mentioned key concept of the LM, a second perspective that informs the current study derives from the landmark work of Fishman's language shift (henceforth LS) (1991 and 2001). In our post-industrial world, LS is a common phenomenon in most developing and developed societies. In conceptualizing 'language shift,' the author follows the view of social dialectologists/sociolinguists and linguistic anthropologists/ethnographers (e.g., Gal, 1978; Smith-Hefner, 2009; Mukherjee \& David, 2011; to name but a few). The extensive body of LS research has been driven by the theory that some language-minority individuals and/or groups are constantly seeking for opportunities of upper social motilities by means of the shift of their languages. Their research shows that LS is the ending result of a single individual or a speech community/group, consciously or unconsciously, for a multitude of reasons after a period of time, substitute the functions previously performed by their mother tongues and/or ethnic languages in domains with a new language or one within their repertoire (the complete loss of their mother tongues and/or ethnic languages).

Over the past years, numerous theories (along with experimental facts) have been proposed to account for the phenomenon of LMLS. Until recently, underlying factors influencing the process of LMLS are explored and documented in existing literature. The study reported in the present thesis builds on and extends the research line in the area of LMLS. Researchers have explored several variables that are seen as predictive of LMLS. The variables in question of interest to sociolinguistic researchers include the following: the size of population (Wang and Chong, 2011), the mode of settlement (concentration or scatter) (ibid), enlarging or shrinking functional domains of the language use (Kim and Starks, 2010), institutional support, similarities between languages and cultures of the homeland and the resettled country, intergroup marriages and exogamous marriages (David and Dealwis, 2011), language attitude (Sallabank, 2013) and language ideology, government-determined language policy and language planning, and family language policy (Hlfearnáin, 2013).

Despite the fact that previous studies provide a long list of fundamental factors that involve in the extent of LMLS, few of them address the following factors: (1) the role of mass media (viewed as a major factor) on the LMLS of dialects or regional varieties of speech and (2) the number of the dialectal speakers (viewed as a minor factor) of the speech communities and language-user groups on the LMLS of dialects. This study is concerned with the two above-mentioned factors, aimed to fill in the knowledge gap of current LMLS literature.

As mentioned in the preceding paragraph, there is scarcity of the current scholarly literature that explores the role of mass media in the distribution and the maintenance of the Chinese dialects in the Mainland China](Chen, 2008; Ma, 2006; Sha 2012; to name but a few). The present study will help better understand the extent of the association between mass media and dialects, by shedding lights on the role of dialectal television series and 
dialectal films (as two representatives of the mass media sector) in the distribution, the spread and the maintenance of the dialects in question.

In addition, a large number of current LMLS literature focus on immigrant (stable immigrant communities) (e.g., Wang and Chong, 2011; Morita, 2007; Zhang, 2010; to name but a few) and indigenous communities (e.g., Meek, 2007; Coronel-Molina and Rodri'guez-Mondoñedo, 2011; to name but a few). However, very few studies focus on non-immigrant and non-indigenous communities. The present research concerns the LMLS of non-immigrant and non-indigenous communities of Cantonese- and Shaan'Xi-speaking population [of the dominant Han ethnicity].

\section{Methodology}

\subsection{Research Questions}

The researcher investigates the extent to which the mass media (major factor) and the number of dialectal speakers (minor factor) to a larger or lesser extent promote the distribution of dialects and maintain the vitality of dialects. In light of this, the answers to the research questions asked below are pursued:

(1) What are the differences between relatively more and less powerful Chinese dialects under study with regard to their respective situations of language maintenance?

(2) What are the social factors (underlying reasons) resulting in such differences?

(3) What is the role of mass media in the distribution, the spread and the maintenance of the Chinese dialects (with a focus on the Cantonese and the Shaanxi dialects, respectively)?

\subsection{Data Collection and Analysis: Data Sources, Sites and Samples, and Instruments}

Collected data are presented in a manner that is intended to be both convincing as actual accounts derived from literature and participants and convincing as analyses. The data presented in the study are derived from three sources, because the researcher adopts a multi-method approach (literature review, interview and observation) to obtain data from a representative sample ( $\mathrm{N}=155$ participants) of the Shaan' $\mathrm{Xi}$ speech communities and language-user groups ( $\mathrm{n}=50$ families/approximately 130 participants) and the Cantonese speech communities and language-user groups ( $\mathrm{n}=25$ participants).

A review of literature ( $\mathrm{N}=$ approximately 50 articles published by referred journals and websites) is another main research method in the current study. Additionally, interviews and observations are conducted to supplement available information derived from the LM literature. Interviews and observations with the Shaan'Xi speech communities and language-user groups and the Cantonese speech communities and language-user groups [in the Mainland China] are conducted. Participants are recruited through the personal network and the snowball sampling strategy (friends' contact) of the researcher. It must be acknowledged that the criteria for the inclusion of the sample are as follows: Essentially, the problematic ethnic identities of the sample lies in the fact that both Shaan'Xi and Cantonese are not themselves fully homogeneous. In spite of this, the sample is recruited on the basis of linguistically heterogeneous dialect groups by the self-identification of participants ( 2 speech groups identified as the Shaan'Xi speech community and the Cantonese speech community). Visits are made to fifty homes to study the vitality of the Shaan'Xi dialect ( $\mathrm{n}=50$ families/approximately 130 participants). Moreover, interviews are held to twenty-five Cantonese speakers ( $\mathrm{n}=25$ participants). Participants respond to a semi-structured interview administered by the researcher during the eleven-month period of March 2013 to February 2014. Interview questions are based upon protocols developed by Lee, Hugo (2011). Furthermore, personal observations of the Shaan'Xi community interactions are made on more than 50 occasions, some located in urban areas (and semi-urban areas) and others in rural areas (and semi-rural areas).

\section{Results and Discussion}

4.1 The Researcher Purports to Offer Short Answers to the Research Question 1 (What Are the Differences between Relatively More and Less Powerful Chinese Dialects under Study with Regard to Their Respective Situations of Language Maintenance?).

Viewed from the perspective of the mass media, relatively more powerful Chinese dialects receive higher audience ratings for their television series and receive higher revenues from their dialectal films' box offices than the less powerful ones. In addition, comparatively more powerful Chinese dialects are used among and across more functional language-use domains than the less powerful ones. 


\subsection{The Researcher Purports to Offer Brief Answers to the Research Question 2 (What Are the Social Factors (Underlying Reasons) Resulting in such Differences?).}

The difference lies in the fact that the relatively more powerful Chinese dialects have more number of dialectal speaking populations than the less powerful ones, among other factors (e.g., the economic of dialect-spoken provinces).

In addition to the aforementioned short answers, the researcher purports to provide three complementary and detailed answers to the research question 1 and 2, using the following three factors in lieu of what she has. One is related to the role of mass media in the distribution, the spread and the maintenance of dialects (major factor), another is concerned with the number of dialectal speakers (minor factor) and the other is the language-use domain (other factor).

\subsubsection{Media (Major Factor)}

Prior to sketching the historical, the geographical and the demographical background (of the number of dialectal speakers and the language-use domain in the proceeding sub-sections), the study reported herein is also designed to shed further light on the relationship between mass media and LM. In lieu of the present sub-section, the researcher examines the purported relationship between the mass media and the Chinese dialects in question. In agreement with Sha (2012), the researcher considers that mass media is found to be one of the most influential factors, among others, in the distribution, the spread and the maintenance of the more powerful Chinese dialects (e.g., Cantonese). It is truism that relatively powerful Chinese dialects (e.g., Cantonese) have a significant number of dialectal speakers compared to their counterparts - less powerful Chinese dialects (e.g., Shaan'Xi). A significant amount of mass media is broadcasted using the Cantonese dialect as a result of it massive speaking population, due largely to the fact that Cantonese speakers are accustomed to watch the television series and dialectal films in the Cantonese dialect.

It should be acknowledged that despite a huge number of the ethnic Shaan'Xi younger age groups (currently living in the Shaan'Xi Province) researched, their language shift to the Mandarin is the factor that they do not support the Shaan'Xi dialectal television series and films, respectively.

\subsubsection{Number of Speakers (Minor Factor)}

One of the measurements (interview protocol) adopted by the researcher is to see how many numbers of dialectal speakers use the two dialects in consideration among and across numerous functional communicative domains. Official demographic websites indicate that no more than half of the total population (37 million speakers) in the Shaan'Xi Province use the Shaan'Xi dialect (Ten Features of the Development of Shaanxi Populations, 2012), whereas Cantonese is the most widely used medium for intra-ethnic communication in the Guangdon Province (38 million speakers) (People's Government of Guangdong Province, 2007). More than 98 - $99 \%$ of the older age group (aged 70 - 85) in the research site of Shannxi Province state that they exclusively use the ShannXi dialect. Only (approximately) $20 \%$ of the middle age group (aged $50-70$ ) of the participants state that they occasionally use some Mandarin. Conversely, Shaan'Xi is the most dominant dialect in the linguistic-and-communicative repertoire for the middle age group (aged $50-70$ ). In a sharp contrast, the younger age group (aged 10 - 30) report that their most dominant variety of speech is Mandarin. In some extreme cases, some early-20-years-old participants only understand the Shaan'Xi dialect (listening comprehension) but with no or little speaking ability (performance) of it. Please see the researcher's comment on the younger age group who are undergoing language shift away from the Shaan'Xi dialect toward the Mandarin in the last paragraph of the preceding sub-section.

\subsubsection{Language-Use Domain (Less Important Factor)}

Both concrete and hypothetical data suggest that the usage of the two dialects in question exist in differing geographical locations and discrete domains, wherein Shaan'Xi is commonly used in the Shaan'Xi Province whereas the Cantonese is not only used in the Mainland China (Guangdon Province and some parts of the Guanxi Province) but also in Hong Kong (Special Administrative Region), Macau (Special Administrative Region) and communities of overseas Chinese immigrants (North America, EU countries, Southeast Asia, among others).

4.3 The Researcher Purports Three Short Answers to the Research Question 3(What Is the Role of Mass Media in the Distribution, the Spread and the Maintenance of the Chinese Dialects (with a Focus on the Cantonese and the Shaanxi Dialects, Respectively)?).

(1). The relatively more powerful Chinese dialects have longer history of the development of their mass media sectors than the less powerful ones; (2).The more powerful Chinese dialects evidently have more numbers of the 
production of the dialectal television series and dialectal films than the less powerful ones by their respective mass media sectors; and (3). The mass media provides institutional support to help the distribution, the spread and the maintenance of the more powerful Chinese dialects than the less powerful ones.

After answering the research question 1 and 2 in the preceding sub-sections, a problem immediately arises for the investigator. The problem is that the historical work and scholarly literature never formally document mass media's alleged factor as the underlying reason for the wide-spread and the well-maintenance of the relatively powerful Chinese dialects (despite the scarcity of scholarly literature address the linkage by Chen, 2008; Ma, 2006; and Sha, 2012). The researcher accordingly inquiries into how the mass media connects to the spread and the maintenance of the two Chinese dialects in consideration. This is principally conducted through a comparison of three main themes explored in details: 1). The history of the dialectal films and integrated televisions (of the two Chinese dialects in consideration), 2). The number of dialectal films and television series being produced (of the two Chinese dialects under investigation), and 3). The box office of the dialectal films and the audience ratings of the dialectal television series (of the two Chinese dialects researched).

Below are the complementary and detailed answers to the research question three. This sub-section presents the history and the development of the Cantonese films that have been generated by the museum of FoShan (佛山, fóshān) (2004). In view of the evidence, the Cantonese films inaugurated the work of the director named Xiao-Dan Tang (湯曉丹, tāng xiăo dān) and his first audible film titled White Gold Dragon (白金龍, bái jīn lóng), which was dubbed in the Cantonese dialect (ibid). Since the early 1930s, the Cantonese films have gained popularity. In the 1950s, the Cantonese films enjoyed their Golden Age (In the 1958 alone, 89 Cantonese films were produced).

Table 1 and the linear graph (Figure 2) below present audience ratings of television series (Source of data: China Central Television - CVSC-SOFRES MEDIA or CSM, July 2009 - May 2010) from Cantonese- and ShaanXi-broadcasting television channels, respectively.

Table 1. Audience ratings of television channels: focus on Cantonese-broadcasting Guangzhou and ShaanXi-broadcasting Xi'an integrated televisions, 2009-2010

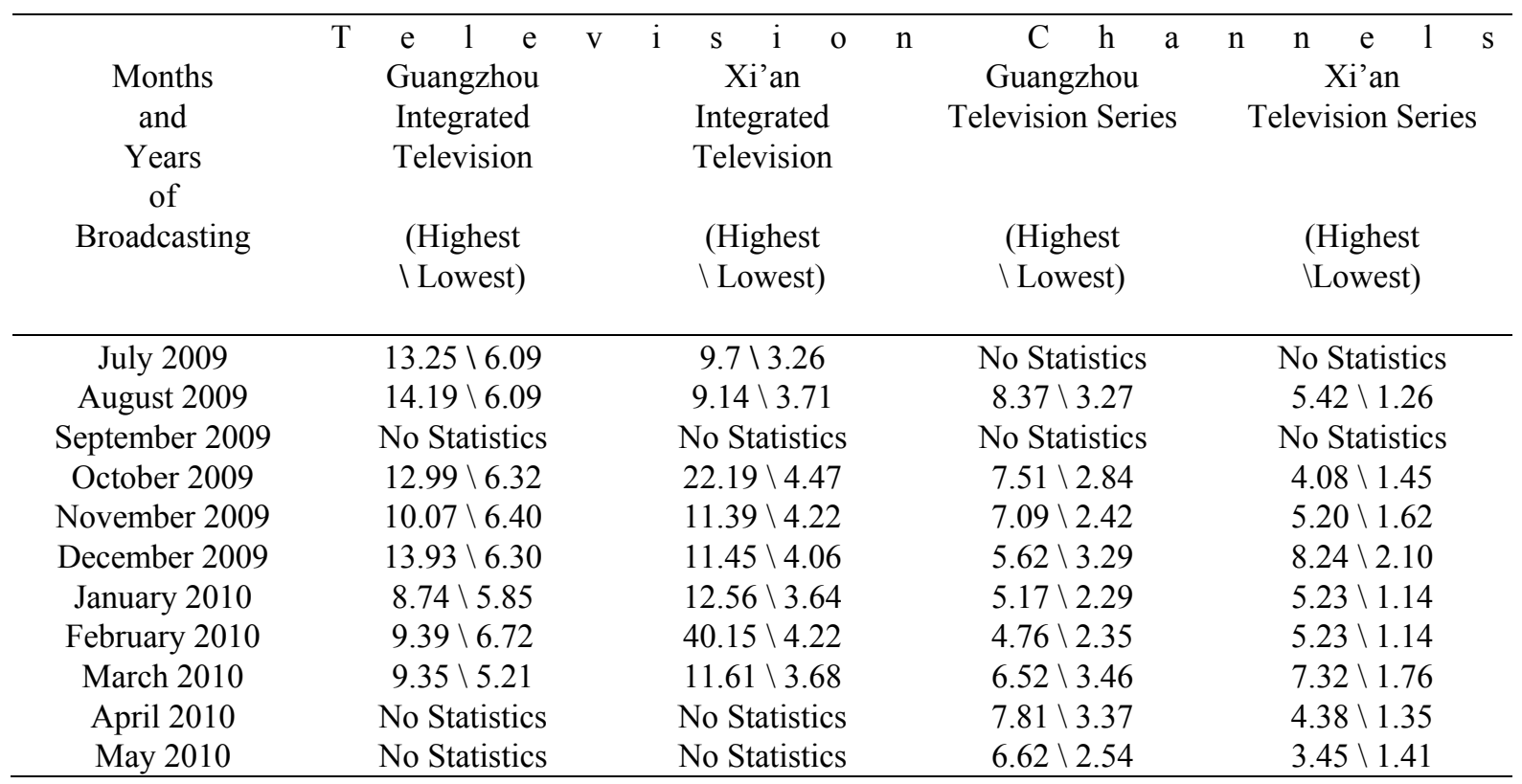

Source: China Central Television - CVSC-SOFRES MEDIA or CSM, July 2009 - May 2010

Table 1 and Figure 2 show that the average (mean) of audience ratings for Cantonese-broadcasting Guangzhou Integrated Television (5-6) is higher than the Shaan'Xi-broadcasting Xi'an counterpart (3-4). Complementary to the audience ratings on the integrated television, the audience rating on the television series broadcasted in the Cantonese dialect (2-3) is higher than its counterpart of Shaan'Xi-broadcasted television series (1-2). Relatedly, according to Table 1 and Figure 2, it can be concluded that the highest audience rating for Cantonese-broadcasting Guangzhou Integrated Television (14.19, July 2009) is higher than the 
Shaan'Xi-broadcasting Xi'an counterpart (11.45, December 2009). In addition, Table 2 reports the box office of Cantonese- and ShaanXi-dialectal films compared to the box office of all Chinese films (excluding all non-Chinese or foreign films in the Mainland China).

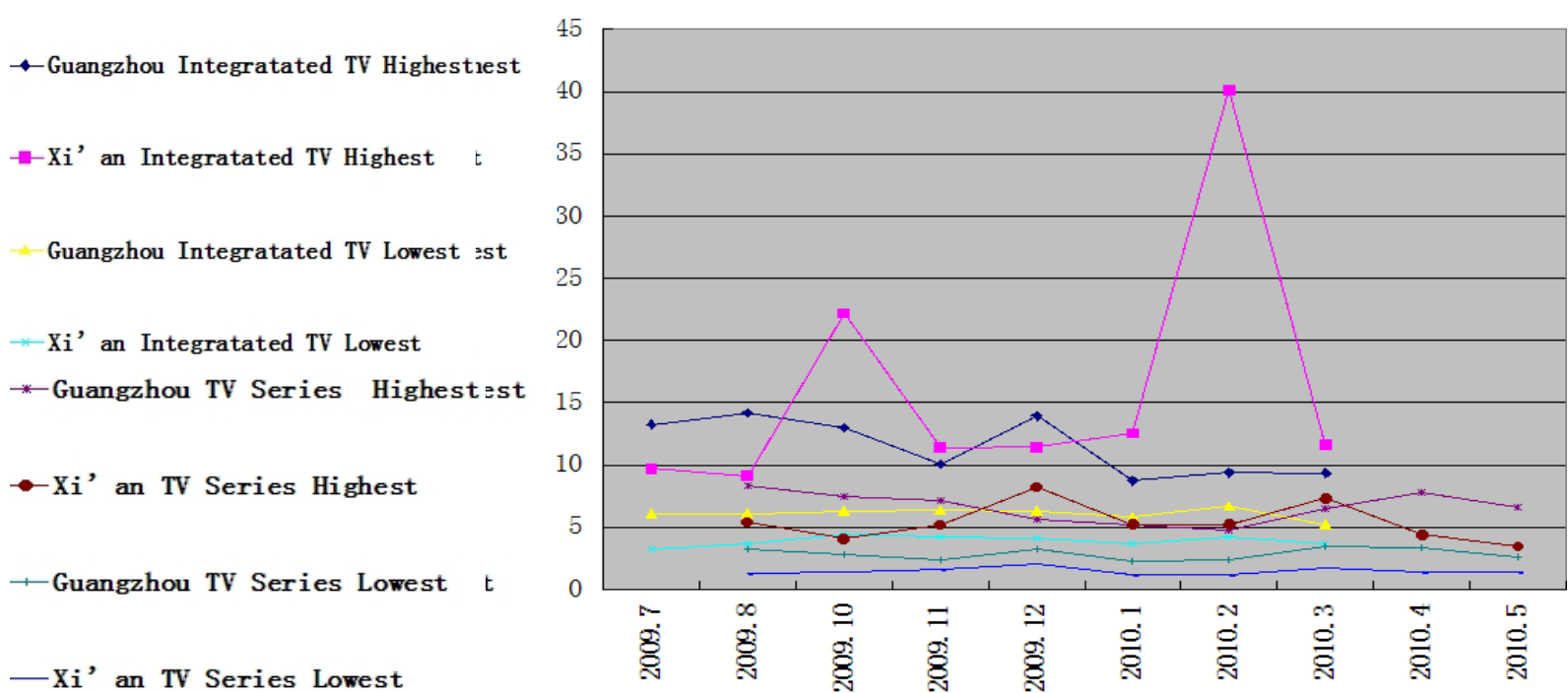

Source: China Central Television - CVSC-SOFRES MEDIA or CSM, July 2009 - May 2010

Figure 2. The Linear Graph of the Audience Ratings of Television Channels (Cantonese-broadcasting Guangzhou and ShaanXi-broadcasting Xi' an Integrated Televisions, 2009 - 2010)

Table 2. The box office of Cantonese- and ShaanXi-dialectal films in comparison of all Chinese films

\begin{tabular}{|c|c|c|c|c|c|}
\hline \multirow[b]{2}{*}{ Years } & \multicolumn{5}{|c|}{ 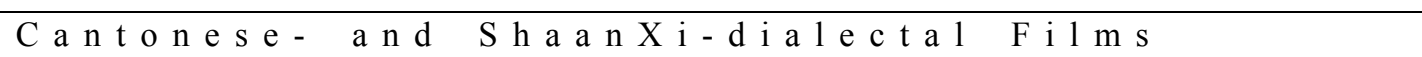 } \\
\hline & $\begin{array}{c}\text { Number of } \\
\text { Cantonese } \\
\text { Films }\end{array}$ & $\begin{array}{l}\text { Box Office of } \\
\text { Cantonese Films } \\
\text { (Measurement of } \\
\text { Box Office: } ¥ \text { Ten } \\
\text { Thousand China } \\
\text { Yuan or CNY) }\end{array}$ & $\begin{array}{l}\text { Number } \\
\text { of } \\
\text { Shaan'xi } \\
\text { Dialectal } \\
\text { Films }\end{array}$ & $\begin{array}{l}\text { Box Office of Shaan’xi } \\
\text { Dialectal Films } \\
\text { (Measurement of Box } \\
\text { Office: ¥ Ten Thousand } \\
\text { China Yuan or CNY) }\end{array}$ & $\begin{array}{l}\text { Annual Revenue from all } \\
\text { Box Office of Chinese } \\
\text { Films in the Mainland } \\
\text { China, excluding all } \\
\text { foreign-language } \\
\text { (non-Chinese) films }\end{array}$ \\
\hline 1995 & 1 & 9,500 & 0 & 0 & 95,000 \\
\hline 1996 & 2 & 13,700 & 0 & 0 & 115,000 \\
\hline 1997 & 1 & 6,500 & 2 & 7,900 & 100,000 \\
\hline 1998 & 1 & 8,000 & 0 & 0 & 140,000 \\
\hline 1999 & 1 & 2,000 & 1 & 3,000 & 81,000 \\
\hline 2000 & 0 & 0 & 0 & 0 & 86,000 \\
\hline 2001 & 2 & 5,500 & 0 & 0 & 89,000 \\
\hline 2002 & 3 & 28,200 & 0 & 0 & 90,000 \\
\hline 2003 & 8 & 11,070 & 0 & 0 & 100,000 \\
\hline 2004 & 6 & 28,440 & 1 & 12,000 & 150,000 \\
\hline 2005 & 13 & 44,955 & 0 & 0 & 200,000 \\
\hline 2006 & 6 & 24830 & 2 & 8500 & 260,000 \\
\hline 2007 & 9 & 53,908 & 3 & 4300 & 330,000 \\
\hline 2008 & 9 & 59,107 & 1 & 4696 & 430,000 \\
\hline 2009 & 9 & 97,760 & 6 & 44,520 & 630,000 \\
\hline 2010 & 12 & 105,710 & 2 & 11,790 & 889,059 \\
\hline 2011 & 12 & 148,415 & 2 & 25,900 & $1,226,420$ \\
\hline $\begin{array}{l}\text { Sources: } \\
<\text { http://ti } \\
\text { Televisio } \\
\text { among } \\
<\text { http://w }\end{array}$ & The ana & $\begin{array}{l}\text { is of movie } \\
\text { 768554148>; Gen }\end{array}$ & $\begin{array}{l}\text { box } \quad 0 \\
1 \text { Admi }\end{array}$ & $\begin{array}{l}\text { in the Main } \\
\text { tration of Press, Pub } \\
\text { tent_1576168.htm>; an } \\
\text { of box office amo } \\
\text { html> }\end{array}$ & $\begin{array}{l}\text { d China, } 1995-2010 \\
\text { ation, Radio, Film and } \\
\text { The ranking of box office } \\
\text { Chinese films, } 2011\end{array}$ \\
\hline
\end{tabular}


Moreover, Figure 3 gives an overview of the box office of the Cantonese- and Shaan'Xi dialectal films, 1995-2011.

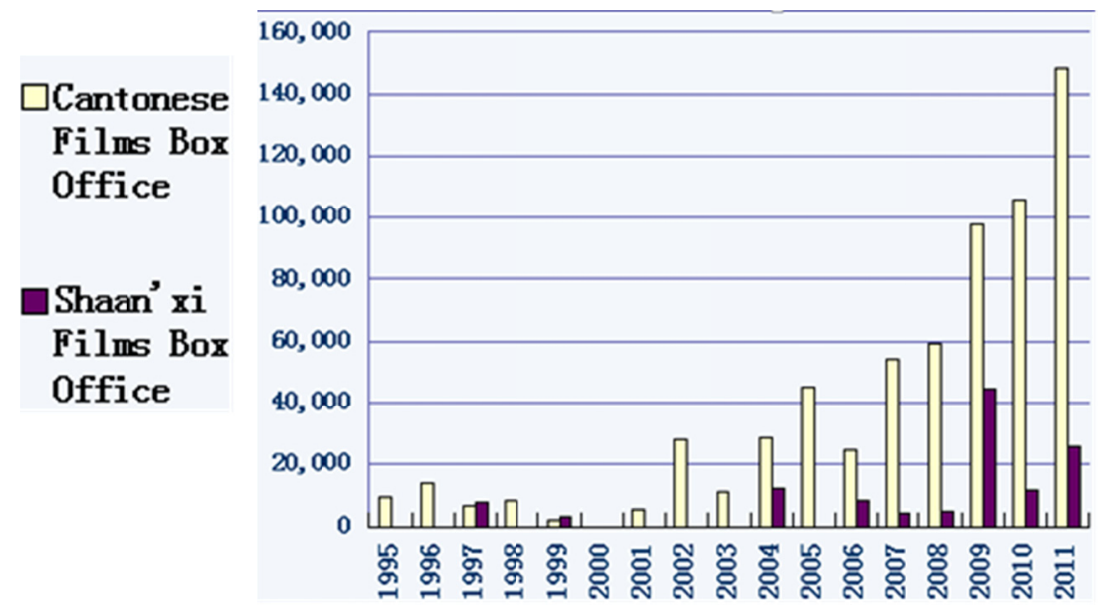

Figure 3. The Box Office of the Cantonese- and ShaanXi-Films, 1995-2011

Sources: The analysis of movie box office in the Mainland China, 1995-2010 $<$ http://tieba.baidu.com/p/768554148>; General Administration of Press, Publication, Radio, Film and Television, $2010<\mathrm{http}: / / \mathrm{www} . g o v . c n / g z d t / 2010-04 / 09 /$ content_1576168.htm>; and The ranking of box office among Chinese films - weekly news for rankings of box office among Chinese films, 2011 $<$ http://wenku.baidu.com/view/43e301214b35eefdc8d33333.html>

Further, the number of manufactured films using the two Chinese dialects under consideration is provided in Figure 4.

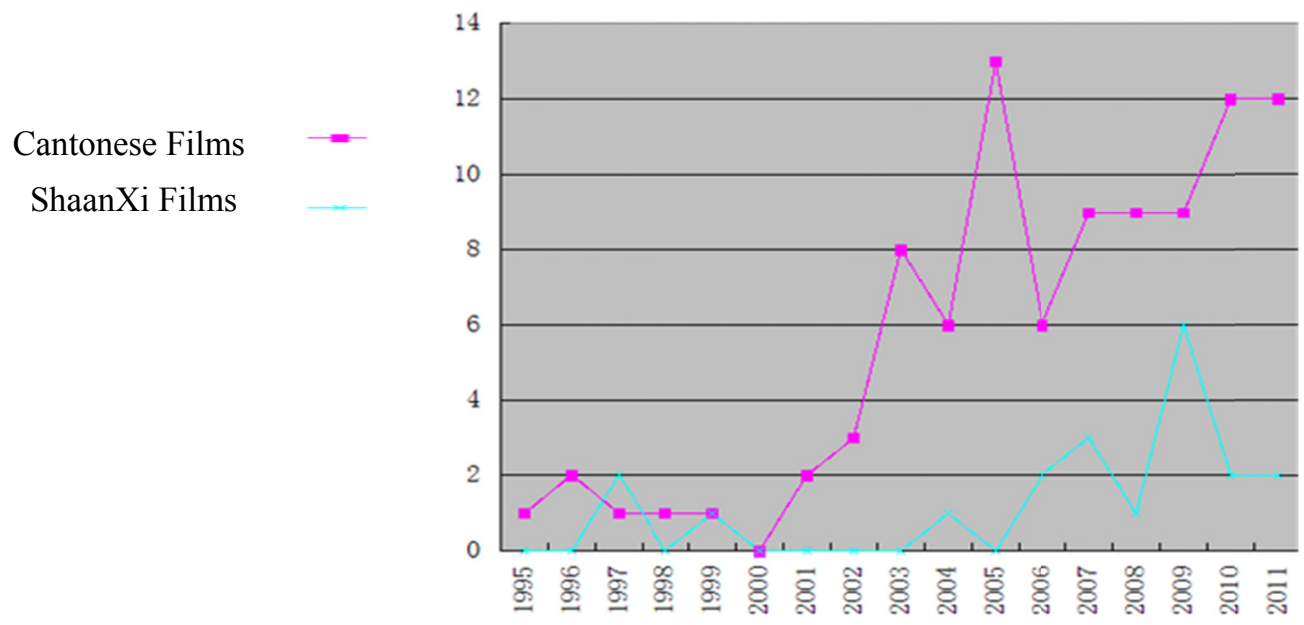

Figure 4. The number of Cantonese and ShaanXi films, 1995-2011

Sources: The analysis of movie box office in the Mainland China, 1995-2010 $<$ http://tieba.baidu.com/p/768554148>; General Administration of Press, Publication, Radio, Film and Television, 2010<http://www.gov.cn/gzdt/2010-04/09/content_1576168.htm>; and The ranking of box office among Chinese films - weekly news for rankings of box office among Chinese films, 2011 $<$ http://wenku.baidu.com/view/43e301214b35eefdc8d33333.html $>$

It has become evident that the mass media - particularly with regard to the film industry - has promoted the Cantonese dialectal films over the ShaanXi dialectal films. As shown in Table 2 and Figure 4, 2005 is the year when the highest number of Cantonese films were produced $(n=15)$, while 2009 is the year when the most number of ShaanXi films were manufactured $(n=6)$.

Here is another example and evidence. In above-mentioned Table 2. Figure 3 and Figure 4, the box office of the Cantonese films was steadily growing from 2002 to 2008 until it reaches its peak in the year of 2011, with an 
estimated revenue of 150,000 China Yuan (or CNY) generated. Whereas, the maximum amount of revenue generated by ShaanXi films was only 45, 000 China Yuan (or CNY) in the year of 2009.

In all cases, the Cantonese films outperform Shaan'Xi films. For instance, the averaged (mean) revenue per day made by the Cantonese film, known as Cold War (寒戰, hán zhàn), was 1,235,088 Hong Kong Dollars (or HKD) (Twenty First CN, 2012) and its 10-day box office was totaled 95,000,000 China Yuan (or CNY) (Mtime.com, 2012, <http://news.mtime.com/2012/11/26/1502092.html>). It is not surprised to see that the revenue made by the Cantonese film of Cold War (寒戰, hán zhàn) during the first week in the movie theaters was totaled 1.8 billion Hong Kong Dollars (or HKD) (Phoenix Blog, 2013, <http://blog.ifeng.com/article/22411823.html>) and its accumulative box office totaled 1.91 billion China Yuan (or CNY) (Mtime.com, 2012, $<$ http://news.mtime.com/2012/11/26/1502092.html>).

In combination of the afore-mentioned analyses of the Cantonese dialectal film of Cold War (寒戰, hán zhàn), the researcher carries out another comparison as follows: In the year of 2012, the Cantonese dialectal film of Cold War (寒戰, hán zhàn) received an above-the-average box office in the Shaan'Xi-speaking Province, while it received much higher box office in Cantonese-speaking regions of the Mainland China than that of ShaanXi Province. By contrast, the Shaan'Xi dialectal film of Gao Xing (高興, gāo xìng) received a relatively higher box office in the Shaan'Xi-speaking Province than other Chinese dialectal films in 2009, whereas its revenue of box office was lower than 10,000 Hong Kong Dollars (or HKD) in the Cantonese-speaking Hong Kong Special Administrative Area in the same year (Liao 1 News, 2010).

\section{Conclusion}

In summary, the current study provides empirical and statistical answers to the question of what is the disparity between relatively powerful and less powerful dialects by exploring sociological factors of the role of mass media (more powerful Chinese dialects receive higher audience ratings for their television series and receive higher revenues from their dialectal film's box offices than the less powerful ones), the number of dialectal speakers (more powerful Chinese dialects have more number of dialectal speaking population than the less powerful ones) and the language-use domain (more powerful Chinese dialects are used among and across more functional language-use domains than the less powerful ones) (Answers to research question 1 and 2).

Despite the aforementioned contributions to the academic literature of dialect studies, LM, and other related fields, the researcher herein acknowledges some limitations of the current study. First, the sample size is rather small. The representative sample ( $\mathrm{N}=155$ participants) of the Shaan'Xi speech communities and language-user groups ( $\mathrm{n}=50$ families/approximately 130 participants) and the Cantonese speech communities and language-user groups $(\mathrm{n}=25$ participants) participated in the present research constitute merely 0.00035 percentage of the total ShaanXi-speaking population ( $\mathrm{n}=$ approximately $37,000,000)$ and 0.00006 percentage of the total Cantonese-speaking population in the Cantonese Province ( $\mathrm{n}=$ approximately 38,000,000), and 0.00035 percentage of the total Cantonese-speaking population in Hong Kong ( $\mathrm{n}=$ approximately 7,130, $000-7,138,000)$ (Source: hk.szhk.com).

Second, in addition to the relatively smaller sample size recruited to participate in the study as being criticized in the preceding paragraph, the other primary data source of the present study is also problematic and questionable--the statistical and numerical data of audience ratings (on the television series under study) and the box office (of the films under consideration). The problem lies in the fact that the mechanism through which the audience ratings of television series and the box office of films are calculated cannot be verified by the researcher herself. Moreover, there is no complementary data to the audience ratings of the television series and the box office of the films researched.

In spite of the above-mentioned criticisms and limitations, the present study potentially benefits the scholarly society, the mass media sector, and the speech community members and/or language-user groups of the endangered languages and/or minority dialects. The present study is aimed to fill in the knowledge gap of scholarly literature about the role of mass media in the distribution, the spread and the maintenance of the endangered languages and minority dialects. This research hereby is and will be of some interests to a considerable number of academics and scholars who carry out their research on endangered languages and minority dialects, but historically overlooked the importance of the role of the mass media. The entertainment sector is another potential beneficiary of the current research report. The study is proven the evidence of making use of the mass media (e.g., dialectal television series and dialectal films) to the extent of the distribution, the spread and the maintenance of the dialects. Moreover, the members of the speech communities and/or language-user groups of the endangered languages and/or minority dialects may potentially benefit from the 
current study by raising their awareness on the maintenance of their less powerful dialects and by embarking their interest in learning the ethnic and/or heritage languages.

Of equal importance to the list of potential benefits to differing sectors from the current study, as reported in the preceding paragraph, is the recommendations and the suggestions to the future researchers (who undertake the research of comparison between more dominant and less dominant dialects in the same nation-state and who carry out research on the distribution, the spread, the maintenance and the shift among and across endangered languages and/or minority dialects under their consideration) based on the present research. The future researchers are suggested to 1). recruit a much bigger sample size of the participants (speech community members and/or language-user group members) to be surveyed, interviewed and observed; and 2) adopt a more objective measurement (instead of subjective measurement) on the popularity and the audience ratings of the dialectal television series and the dialectal films, respectively. Moreover, future researches are hereby advised to take into account the role of mass media (which has been conventionally under-addressed by previous researchers in media studies, dialect studies and sociolinguistic studies of language maintenance and shift, among others), particularly the dialectal television series and the dialectal films, on the extent of the vitality, maintenance, shift and extinction of dialects in question.

\section{References}

Appel, R., \& Muysken, P. (1987). Language Contact and Bilingualism. London: Edward Arnold.

Baidu. (2010). Analysis of Audience Ratings, 1995 2010 (In Chinese). Retrieved March 22, 2014, fromhttp://tieba.baidu.com/p/768554148

Baidu. (2011). Rankings of Chinese Films in 2011 (In Chinese). Retrieved March 22, 2014, from http://wenku.baidu.com/view/43e301214b35eefdc8d33333.html

Baker, C., \& Jones, S. P. (1998). Encyclopedia of Bilingualism and Bilingual Education. Clevedon, UK: Multilingual Matters.

Boeije, H. (2010). Analysis in Qualitative Research. Thousand Oaks, CA: SAGE Publications Ltd.

Chen, Y. Y. (2008). An analysis of the dialectal fever in the films and television series. Film Literature (In Chinese). Retrieved March 22, 2014, from http://www.cnki.com.cn/Article/CJFDTotal-DYLX200805068. htm

China Central Television. (2009). Rankings of Audience Ratings on Television Channels (In Chinese). Retrieved March 22, 2014, from http://xianfeng.cctv.com/02/20091016.shtml

Chun, Y. H. (2006). The Vast Territory of China (In Chinese). Retrieved on December 23, 2013, from http://news.sohu.com/20061208/n246904062.shtml

CNWEST. (2009). <Gao Xing > Won the Highest Box Office in the Year of Ox (In Chinese). Retrieved March 22 , 2014, from http://news.cnwest.com/content/2009-02/06/content_1784074.htm

Coronel-Molina, S. M., \& Rodrı'guez-Mondon edo, M. (2011). Introduction: Language contact in the Andes and universal grammar. Lingua, 122, 447-460. http://dx.doi.org/10.1016/j.lingua.2011.11.013

David, M. K., \& Dealwis, C. (2011). Do exogamous marriages result in language shift. In D. Mukherjee, \& M, K. David (Eds.), National Language Planning and Language Shifts in Malaysian Minority Communities (pp. 59-70). Leiden: International Institute of Asian Studies/Amsterdam: Amsterdam University Press.

Ding, B. X. (1998). Hanyu Fangyan qufen de tiaojian [Featuresfor the classification of Chinese dialects] (In Chinese, pp. 166-187).

Fishman, J. A. (Ed.). (1991). Reversing Language Shift: Theoretical and Empirical Foundations of Assistance to Threatened Languages. Clevedon: Multilingual Matters Ltd.

Fishman, J. A. (Ed.). (2001). Can Threatened Languages be Saved: Reversing Language Shift Revisited: A 21st Century Perspective. Clevedon: Multilingual Matters Ltd.

Gal, S. (1978). Men can't get wives: Language change and sex roles in a bilingual community. Language in Society, 7(1), 1-16. Cambridge: Cambridge University Press. http://dx.doi.org/10.1017/S004740450000 5303

Gao, Y. F. (2004). A brief introduction of the development of Cantonese films (In Chinese). Foshan Daily, (44). etrieved March 22, 2014, from http://www.foshanmuseum.com/wbzy/xslw_disp.asp?xsyj_ID=27

Cao, Z. Y. (2001). Endangered Chinese Dialects (In Chinese). Language Teaching and Linguistic Studies, 5, 
10-14. Retrieved December 28, 2013, from http://yys.blcu.edu.cn/8_award/wenzhang/binweifangyan.htm

Giles, H., Bourhis, R., \& Taylor, D. M. (1977). Towards a theory of language in ethnic group Relations. In H. Giles (Ed.), Language, Ethnicity and Intergroup Relations (pp. 307-348). London: Academic Press.

Hlfearnáin, T. (2013). Family language policy, first language Irish speaker attitudes and community-based response to language shift. Journal of Multilingual and Multicultural Development, 34(4), 348-365. http://dx.doi.org/10.1080/01434632.2013.794809

Jin, X. K., \& Ma, Y. J. (2011). An exploration of the meaning of the maintenance and the transmission of dialects (In Chinese). Journal of Heilongjiang College of Education, (5), 127-130.

Kim, S, H, O., \& Starks, D. (2010). The role of fathers in language maintenance and language attrition: The case of Korean-English late bilinguals in New Zealand. International Journal of Bilingual Education and Bilingualism, 13(3), 285-301. http://dx.doi.org/10.1080/13670050903193958

Kurpaska, M. (2010). Chinese Language(s): A Look through the Prism of the Great Dictionary of Modern Chinese Dialects. Berlin, Germany: De Gruyter Mouton. http://dx.doi.org/10.1515/9783110219159

Lee, Hugo, Y.-H. (2011). Designing a course packet for qualitative research methodology in language and communication studies: Together with a tipbook to write a fast qualitative research paper. Columbus, Ohio: The Educational Publisher, Inc.

Li, F. K. (1937). Chinese Languages and Dialects (In Chinese). Beijing: Qinghua University Press.

Li, R. L. (2002). Hanyu Fangyan Tezheng Ci Yanjiu [The study of characteristic Chinese dialectal words] (In Chinese). Xiamen: Xiamen Daxue Chubanshe.

Liao 1 News. (2010). Avatar: The box office in Hong Kong is soon over billions. Laio 1 News. Retrieved March 29, 2014, from http://news.liao1.com/newspage/2010/01/4369489.html

Lin, J. (2011). 2500 Languages Facing Extinct around the Globe (In Chinese). Retrieved December 23, 2013, from http://tech.sina.com.cn/d/2011-05-27/15005580437.shtml

Lin, Y. (2008). The origin of the phenomenon of dialectal television cultures (In Chinese). Youth Journalist. Retrieved December 24, 2013, from http://qnjz.dzwww.com/gdst/200802/t20080203_3189426.htm

Lu, D. (2002). English Medium Teaching at Crisis: Towards Bilingual Education in Hong Kong. GEMA Online Journal of Language Studies, 2(1). Retrieved December 28, 2013, from http://ejournal.ukm.my/gema/issue/ view/86

Ma. K. (2006). Dialectal films: The awaken-ness and deepen-ness of cultural consciousness. Sina Center for News Press (In Chinese). Retrieved March 29, 2014, from http://news.sina.com.cn/c/2006-09-19/ 151811049809.shtml

Meek, B. A. (2007). Respecting the language of elders: Ideological shift and linguistic discontinuity in a Northern Athapascan community. Journal of Linguistic Anthropology, 17(1), 23-43. http://dx.doi.org/10. 1525/jlin.2007.17.1.23

Morita, L. (2007). Discussing assimilation and language shift among the Chinese in Thailand. International Journal of Sociology of Language, 186, 43-58.

Mtime. (2012). Chronicle of Films and Televisions: $<$ Cold War $>$ Won the Box Office in Two Consecutive Weeks (In Chinese). Retrieved March 22, 2014, from http://news.mtime.com/2012/11/26/1502092.html

Mukherjee, D., \& David, M. K. (Eds.). (2011). National Language Planning and Language Shifts in Malaysian Minority Communities: Speaking in Many Tongues. Amsterdam: Amsterdam University Press.

Norman, J. (1988). Chinese. Cambridge: Cambridge University Press.

Peng, L. (Ed.). (2013). Summary of the Characteristics of the Shaanxi People by Internet Users (In Chinese). Retrieved December 28, 2013, from http://xianyang.hsw.cn/system/2013/10/17/051776400_01.shtml

People's Government of Guangdong Provence. (2007). Characteristics of Dialects (In Chinese). Retrieved on December 27, 2013, from http://www.gd.gov.cn/gdgk/sqgm/sdmx/200709/t20070912_19871.htm

Sallabank, J. (2013). Can majority save an endangered language? A case study of language attitudes in Guernsey. Journal of Multilingual and Multicultural Development, 34(4), 332-347. http://dx.doi.org/10.1080/ 01434632.2013.794808

Sha, Y. J. (2012). The Spread of the Shaanxi Dialect via Films and Television Dramas (In Chinese). Retrieved 
December 23, 2013, from http://www.doc88.com/p-9366349234639.html

Smith-Hefner, N. J. (2009). Language shift, gender, and ideologies of modernity in Central Java, Indonesia. Journal of Linguistic Anthropology, 19(1), 57-77. http://dx.doi.org/10.1111/j.1548-1395.2009.01019.x

SZHK. (2013). Census Data of Hong Kong in 2013 (In Chinese). Retrieved March 22, 2014, from http://hk.szhk.com/2013/08/13/282849380203197.html

Tang, L. (2010). The endangered situation and the factor analysis of the Xiangnan local vernacular (In Chinese). Modern Chinese. Retrieved December 28, 2013, from http://www.docin.com/p-373744772.html

The State Administration of Radio, Film and Television (2010). Audience Ratings of Films during the First Season of 2010 (In Chinese). Retrieved March 22, 2014 from http://www.gov.cn/gzdt/2010-04/09/ content_1576168.htm

Twenty First CN. (2012). Summary of Box Offices of Hong Kong Films (In Chinese). Retrieved March 22, 2014, from http://et.21cn.com/gundong/etscroll/2012/11/19/13712782.shtml

Wang, C. (2011). I am a spoken person for the SuXian dialect (In Chinese). Sqdaily. Retrieved December 24, 2013, from http://epaper.sqdaily.com/sqwb/html/2011-08/09/content_251782.htm

Wang, L. (1936/1982). Zhongguo Yinyunxue [Chinese phonology] (In Chinese). Shanghai: Shangwu Yinshuguan.

Wang, X., \& Chong, S. L. (2011). A hierarchical model for language maintenance and language shift: Focus on the Malaysian Chinese community. Journal of Multilingual and Multicultural Development, 32(6), 577-591. http://dx.doi.org/10.1080/01434632.2011.617820

$\mathrm{Xu}, \mathrm{L}$. (2012). Factors that influence the discrepancy of [the maintenance and the shift of] dialects (In Chinese). China Science \& Technology Education, 190. Retrieved December 26, 2013, from http://www.chinaqking. $\mathrm{com} / \mathrm{yc} / 2012 / 221747 . \mathrm{html}$

Yang, S. N., \& Xu, J. (2009). The formation of Heilongjiang Zhan dialect and its main characteristics. Journal of Daqing Naormal University, 5(29). Retrieved December 28, 2013, from http://wenku.baidu.com/link?url =lUT1F6WoBWvwDRpIqxRp89wFngG6KN70ftdSqXvphhbFEpqGQnYVTYfOz_1Chhia1soEjdOR5mq8 PGfMUPypksusksixlwNB11k9PAcPLK

Zhan, B. H. (1981). Xiandai Hanyu fangyan [Modern Chinese dialects] (In Chinese). Wuhan: Hubei Renmin Chubanshe.

Zhang, J. (2010). Parental attitudes toward Mandarin maintenance in Arizona: An examination of immigrants from the People's Republic of China. Critical Inquiries in Language Studies, 7(4), 237-269. http://dx.doi.org/10.1080/15427587.2010.527563

\section{Copyrights}

Copyright for this article is retained by the author(s), with first publication rights granted to the journal.

This is an open-access article distributed under the terms and conditions of the Creative Commons Attribution license (http://creativecommons.org/licenses/by/3.0/). 